\title{
Erratum to: The Trial to Reduce IDDM in the Genetically at Risk (TRIGR) study: recruitment, intervention and follow-up
}

The TRIGR Study Group

Published online: 7 June 2011

(C) Springer-Verlag 2011

\section{Erratum to: Diabetologia}

$$
\text { DOI 10.1007/s00125-010-1964-9 }
$$

Unfortunately the ESM for this paper was incorrect. The corrected ESM Table 1 contains a list of the TRIGR Study Group Investigators and the corrected ESM Table 2 contains a list of TRIGR administration centres, and participating countries and centres.

The online version of the original article can be found at http://dx.doi. org/10.1007/s00125-010-1964-9.

Electronic supplementary material The online version of this article (doi:10.1007/s00125-011-2209-2) includes details of the TRIGR Study Group Investigators, plus a complete list of TRIGR

administration centres, and participating countries and centres, and is available to authorised users.

H. K. Åkerblom $(\bowtie)$

Hospital for Children and Adolescents, University of Helsinki, Biomedicum Helsinki 2 U, PO Box 20, 00014, Helsinki, Finland

e-mail: hans.akerblom@helsinki.fi 